\title{
Medical Consequences of Marijuana Use: A Review of Current Literature
}

\author{
Adam J. Gordon • James W. Conley • Joanne M. Gordon
}

Published online: 14 November 2013

(C) Springer Science+Business Media New York (outside the USA) 2013

\begin{abstract}
With the advent of legalization of marijuana for medicinal and recreational purposes, and the increase use of marijuana, healthcare providers will be increasingly confronted with marijuana users as patients in clinical environments. While there is vast literature regarding the societal and mental health harms associated with marijuana use, there is a paucity of reviews of the potential consequences of marijuana use on physical health or medical conditions. We examine the recent literature on the physical harms associated with illicit and legal marijuana administration. We surveyed the peer-reviewed medical literature from 1998 to 2013 of studies assessing the association of marijuana use and physical diseases. We conclude that healthcare providers should be cognizant that the existing literature suggests that marijuana use can cause physical harm. However, evidence is needed, and further research should be considered, to prove causal associations of marijuana with many physical health conditions.
\end{abstract}

Keywords Marijuana $\cdot$ Medical consequences $\cdot$ Review . Substance use and related disorders $\cdot$ Psychiatry

This article is part of the Topical Collection on Substance Use and Related Disorders

\section{A. J. Gordon $(\bowtie) \cdot J$. W. Conley}

Center for Health Equity Research and Promotion (CHERP), VA

Pittsburgh Healthcare System, 151-C, University Drive C,

Pittsburgh, PA 15240-1001, USA

e-mail: gordona@medschool.pitt.edu

\section{A. J. Gordon · J. W. Conley}

Mental Illness Research, Education, and Clinical Center (MIRECC),

VA Pittsburgh Healthcare System, Pittsburgh, PA, USA

\section{J. M. Gordon}

Missouri State University, Springfield, MO, USA

\section{A. J. Gordon}

University of Pittsburgh School of Medicine, Pittsburgh, PA, USA

\section{Introduction}

The legal and illicit use of marijuana is increasing. In the USA, 16 states have legalized marijuana use for medical purposes, with more currently considering some form of legalization for medical or non-medical use [1]. This legislative trend runs counter to US law, which still prohibits the production, sale, procurement, and use of marijuana independent of purpose. Marijuana has been designated a Scheduled I medication by the US Drug Enforcement Agency, indicating that marijuana is among "the most dangerous class of drugs with a high potential for abuse and potentially severe psychological and/ or physical dependence" [2], although the rationale for this assessment has been controversial [3-6]. Recently, the American Psychiatric Association's revised Diagnostic and Statistical Manual of Mental Disorders affirmed that marijuana use can progress to a diagnosis of marijuana use disorder, a condition requiring treatment [7].

Cannabis is the world's most widely used illicit substance. In 2010 , as much as $5 \%$ of the world's population had used marijuana [8]. In 2012, more than 100 million people in the USA ( $42 \%$ of the population) had ever used marijuana and more than 30 million (12\%) had used marijuana in the previous year [9]. Use by underage populations within the USA has risen over the last ten years [10]. Marijuana use is particularly high among youth and young adults: $23 \%$ of high school students have used in the previous month [11], $40 \%$ of high school seniors have ever used marijuana [10], and $56 \%$ of young adults had used marijuana in their lifetime [10]. The incidence of marijuana use disorder is increasing [12, 13]. With the advent of legalization of marijuana use for medicinal and recreational purposes, and the increase in prevalence of marijuana use disorder, healthcare providers will be increasingly confronted with marijuana users as patients in their clinical environments. Addressing the potential medical harms of recreational, incidental, and pathologic marijuana 
use will be more important as increasing numbers of these patients access healthcare environments.

While much is known about the psychological, legal, and societal effects of marijuana, less is known about how marijuana affects body systems and incites acute or chronic physical or medical harms. In addition, because the use of medical marijuana is not approved by the US Food Drug Administration, practitioners have little reference to the side effects that result from marijuana's medicinal application. Paradoxically, practitioners need for more information regarding potential side effects, medication interactions, and medical and mental health morbidity is precluded by its recognition as a Schedule I drug by the USA. Orallyadministered medications that use marijuana constituents (e.g., Sativex), contain synthetic products found in marijuana (e.g., dronabinol), and/or contain chemicals similar to marijuana (e.g., nabilone) are approved in various countries. However, these derivative medications offer little insight into the potential physical harms of recreational, medicinal, or illicit inhaled marijuana.

We have previously reviewed the latest literature regarding association of marijuana and physical illness [14]. In addition, several reviews of the medical consequences of marijuana use have concentrated on the mental health, societal, and environmental harms of the substance [12, 15-18]. Recent increases in medicinal, recreational, and pathologic marijuana use, as well as emerging literature, require a critical reevaluation of the medical harms of marijuana.

In this review, we examined the recent peer-reviewed literature (MEDLINE and PubMed from 1998 to August 2013) to identify, review, and report on potential medical harms of marijuana. We concentrated this review on the medical consequences associated with the administration of marijuana. We reviewed recent peer-reviewed literature that indicates a possible association between marijuana use and physical health conditions, grouped by body systems, including immunologic, neoplastic, respiratory, cardiovascular, neurologic, renal and urologic, gastrointestinal, gynecologic, and metabolic. We also review marijuana effects on human physiology and speculate about future research needed to explore the medical harms associated with marijuana administration.

We did not review, in part because the literature is already well reviewed, published work regarding harms associated with such activities of procurement (e.g., legal problems, criminality); physical complications due to use (e.g., trauma due to blunted sensorium); risky practices when using (e.g., risky sexual behaviors); problems in pregnancy, including development of the embryo/fetus (e.g., neurological disorders) [19-24]; or increases or incidence of mental disorders or disease (e.g., psychosis) [25]. We also did not review the concerns of adherence to medicinal treatment, including medication adherence, in persons who use marijuana.

\section{Marijuana Physiology}

Marijuana is a heterogeneous and diverse product when procured both legally and illicitly. Marijuana contains bioactive substances that can produce presumptive and realized pathological responses and diseases in humans. Three classes of cannabinoids are known: the phytocannabinoids (PC) from Cannabis sativa; the endocannabinoids that are endogenous in mammals and other animals; and the synthetic cannabinoids. The physiologic chemicals in marijuana are PC from C. sativa . More than 60 cannabinoids have been identified in marijuana; however, the three most abundant and most often studied are tetrahydrocannabinol (THC), cannabindiol (CBD), and cannabinol (CBN). THC is the psychoactive $\mathrm{PC}$ and is a partial agonist for $\mathrm{CB} 1$ and $\mathrm{CB} 2$ receptors. $\mathrm{CBD}$ has no psychotropic effects. $\mathrm{CBN}$ is a degradation product of THC and has a mild psychotropic effect. In humans, the CB1 receptors are primarily found in the central nervous system (CNS) and the CB2 receptors are primarily found in peripheral tissue, including cells involved in inflammation and immunity.

The endocannabinoids include arachidonyl ethanolamide; 2-arachidonyl glycerol, n-arachidonyl-dopamine, and virodhamine. A fifth possible endocannabinoid is 2arachidonyl glycerol ether. The endocannabinoids are intercellular messengers derived from arachidonic acid. As lipophilic compounds, they are integral to the cell membrane and found in the central and peripheral nervous systems, and other body tissue, where they interact with endogenous cannabinoid receptors (CB1 and CB2) and other receptors. Although the functions of the endocannabinoids are not entirely elucidated, the endocannabinoids seem to have important functions including fetal development and the immune system. Several endocannabinoid-receptor systems have been described and, besides CB1 and CB2 receptors, other atypical receptors have been found that bind with various cannabinoid compounds.

\section{Infectious Disease Risk}

Owing to potential immune dysfunction, marijuana use may increase risk of a variety of infectious agents. Marijuana decreases immune cell activity, suggesting that use of marijuana can lead to an increased susceptibility to a widerange of infections [26]. The role of cannabinoids in suppressing the inflammatory response and immunity may also decrease resistance to various infectious agents [27]. For example, two case studies described outbreaks of tuberculosis (TB) in marijuana users [28, 29]. One case study followed 11 youths smoking marijuana in a closed car and contracting the same TB isolate. Interestingly, 14 of their friends also tested positive for TB, suggesting that TB can be transmitted more readily in socially-linked marijuana users 
[29]. The risk of TB transmission can be potentially as high as two-fold in marijuana users [28].

Social networks combined with impaired immune function among marijuana users may also have had a role in an outbreak of Neisseria meningitides, where both the users and the contacts were linked to marijuana use [30, 31]. Sexually-transmitted diseases are also associated with marijuana use, although it is unclear whether the risky sexual practices and/or impaired immune function may primarily be contributory [32]. Co-users of marijuana, methaqualone, and tobacco users had a higher prevalence and density of oral candida than non-smokers [33, 34].

Marijuana users' risk of developing severe steatosis (fatty degeneration) and fibrosis in the liver through infectious virus vectors has been evaluated. For example, in a sample of 315 patients with untreated chronic hepatitis $\mathrm{C}$ who underwent liver biopsy, one study found that marked hepatic steatosis was (1) associated with daily marijuana use; (2) more often seen in daily marijuana users than occasional users; and (3) more often seen in daily users compared with non-users even when hepatitis $\mathrm{C}$ genotype and alcohol use was considered [35]. Researchers in another study found that after adjustment for other factors like alcohol use, daily marijuana use was associated with moderate-to-severe fibrosis in patients with chronic hepatitis $\mathrm{C}$ [36].

In summary, a few studies explore the relationship between infections and marijuana use outside of risky behaviors associated with marijuana use. Compared with the general population, marijuana users may be more prone to viral and some bacterial infections, including TB. Based on research regarding the harm of marijuana use in patients with chronic hepatitis $\mathrm{C}$, its use in these patients may be deleterious.

\section{Cancer Disease Risk}

Marijuana could be potentially carcinogenic. Cannabinoids have been shown to suppress immune function and increase tumorigenic reactive oxygen species, and marijuana tar contains carcinogens similar to the tar in cigarettes [37]. Unfortunately, methodological limitations in many of the reviewed studies, including selection bias, small sample size, limited generalizability, and lack of adjustment for tobacco smoking, may limit the ability to attribute cancer risk solely to marijuana use [37, 38]. In addition, as pre-malignant changes and cancer development may take some time to develop and marijuana exposure tends to occur in youth and young adults, studies may not have enough follow-up time to explore marijuana's carcinogenic risk. In one review, marijuana smoking was associated with changes in alveolar macrophage and bronchial mucosal function but when adjusted for tobacco use the studies did not show a significant association between marijuana use and lung cancer [39]. There have been series of literature reviews associated with marijuana smoking and cancer $[39,40]$.

Recently, in another review, two cohort studies and 14 casecontrolled studies were described [38]. The cohort studies explored the association between marijuana use and adultonset gliomas, lung, colorectal, prostate, and cervical cancer. Many of the studies had conflicting results or lacked a statistically significant association between marijuana use and cancer. The review points out some limitations of the studies, including possible under-reporting of self-marijuana use, small sample size, and confounders, such as concurrent tobacco smoking. In a case-control study from 1999, 173 patients with squamous cell cancer (SCC) of the head and neck along with 176 cancer-free participants were examined, and investigators found that marijuana smokers had an increased risk for cancer than non-smokers [41]. Interaction effects were found with marijuana use and cigarette smoke, mutagen sensitivity, and use of alcohol. In a recent, large population-based casecontrolled study, with adjustments for sex, education, birth year, alcohol use, and cigarette use, there was no significant association between oral cancer risk and marijuana use [42].

There seems to be an association in the literature with marijuana use and bladder cancer [43]. In a case-control study of a convenience sample of men diagnosed with transitional cell bladder cancer involving age-matched controls with no history of cancer, a statistical difference in cancer occurred with those persons who were habitual marijuana users, including associations of marijuana use and stage, grade, and recurrence of the cancer [44]. Several recent studies suggest an association between marijuana use and testicular germ cell tumors [45-47].

Considering the route of exposure to inhaled marijuana, risk for cancers of the head, neck, and pharyngeal areas could be likely. In a population-based case control study, with adjustments for sex, education, birth year, alcohol use, and cigarette use, there was no significant association between oral SCC risk and marijuana use [42]. Similarly, in a large sample of patients with head and neck cancer, for those who ever smoked marijuana, there was no increased risk of cancer nor was there an association in those smoking one joint per day for 1 year. However, there was an increased risk of head and neck cancer in those who had smoked marijuana for more than 20 years and were never alcohol users compared with marijuana users who never used tobacco [48]. In another case-controlled study, no significant risk for head and neck cancer occurred for those people who had ever used marijuana; however, there was indication that higher exposure may lead to a greater risk [49]. Several other studies have not been conclusive to attribute risk of marijuana to esophageal and pharyngeal cancers when adjusted for confounders, especially cigarette smoking [50].

The risk of lung cancer has been examined in marijuana users. In a case-control study of lung cancer in marijuana 
users, 149 hospitalized lung cancer patients were compared to 188 control participants [51]. When adjusted for age, tobacco use, and occupational exposures, there was an increased risk for the development of lung cancer in those who used marijuana, but that risk was less than that faced by tobacco users. In a 2008 case-control study, participants were interviewed to assess risk factors for lung cancer [52]. Seventy-nine individuals with lung cancer (aged 55 years or younger) were compared with 324 randomly-selected control participants. After adjusting for cigarette smoking and other confounding variables, for each joint-year of cannabis smoking there was an $8 \%$ increased risk of developing lung cancer. When using cigarette pack/year and adjusting for marijuana use, there was a $7 \%$ increased risk of developing lung cancer. After adjusting for cigarette smoking, this group had an increased risk of lung cancer with long-term use of marijuana. In another retrospective study involving a review of surgical pathology, regular marijuana use was thought to be a risk for developing lung cancer [53].

In summary, there does appear to be an increased risk of cancer (particularly head and neck, lung, and bladder cancer) for those who use marijuana over a period of time, although what length of time that this risk increases is uncertain. In addition, this risk may be related to the carcinogenic materials in marijuana, as well the smoke produced in inhalation. Although this risk may not be comparable to the risk of tobacco users, with long-term use and concurrent use of tobacco and alcohol the risks for cancer seem to increase for marijuana users.

\section{Oral Cavity Disease Risk}

Various oral cavity diseases and disorders have been associated with marijuana use, including abnormal oral dryness, caries, severe inflammation of the gums and dental framework leading to loosening of the teeth, and mucosal abnormalities [34]. In addition, marijuana users may have a higher incidence of dental caries and periodontal disease, but this may be associated with poor hygiene rather than direct effects of inhaled marijuana [54]. Grayish-white lesions, dry mouth, and traumatic ulcers were found to be more prominent in marijuana smokers than non-smokers [55]. The degree of periodontal attachment loss seems to be more prominent in marijuana smokers than non-smokers [56]. In this study, although tobacco smokers had periodontal disease, no interaction between marijuana use and tobacco smoking was found in predicting periodontal disease.

\section{Pulmonary Disease Risk}

Inhaled marijuana could incur a risk to pulmonary disease, and numerous studies have been published regarding the effect of marijuana on respiratory dysfunction. Case studies tend to report unusual conditions such as spontaneous pneumothorax or small-cell lung cancer in young adults. An increase in the number of longitudinal studies based on large databases has added to what is known about the effects of marijuana on the respiratory system. An expert review by Lee and Hancox [57•] suggested that marijuana and tobacco smoking have different effects on lung function. Some of the 14 studies reviewed showed an association between marijuana use and large airway inflammation and symptoms of bronchitis, as well as increased airway resistance and changes in dynamic respiratory function tests that measure air volume and velocity on expiration.

Typical respiratory function tests measured in marijuana and tobacco studies include forced vital capacity (FVC) that measures the volume of air in a forced expiration; forced expiratory volume in $1 \mathrm{~s}\left(\mathrm{FEV}_{1}\right)$, the volume forcefully expired in $1 \mathrm{~s}$; total lung capacity (TLC); residual volume of air in the lung at the end of a forced expiration; and functional residual capacity (FRC), the volume of air remaining in the lung after a normal expiration. Decreased $\mathrm{FEV}_{1}$ is typically associated with both obstructive diseases, such as asthma, chronic bronchitis, and emphysema, and restrictive diseases, such as pulmonary fibrosis or other lung tissue dysfunction. The ratio of $\mathrm{FEV}_{1}$ to $\mathrm{FVC}$ is often low in both restrictive and obstructive lung disease.

Two large, longitudinal cohort studies found differing results in their studies of the association between marijuana and tobacco use with adverse pulmonary function. Hancox et al. [58 ] compared spirometry tests of marijuana users and cigarette smokers. A cohort of participants $(n=972$ men and women) had spirometry tests at the age of $9,11,13,15,18,21$, 26 , and 32 years. The changes in the marijuana users in the study were independent of the effects of tobacco smoke. Compared with cigarette smokers, and adjusting for tobacco exposure, marijuana use was significantly associated with higher FVC; however, there was no significant association with $\mathrm{FEV}_{1}$ or $\mathrm{FEV}_{1} / \mathrm{FVC}$ ratio, suggesting that there was no indication of chronic obstructive pulmonary disease. Marijuana use was consistently associated with increases in TLC, FRC, residual volume, and alveolar volume. This increased lung volume in marijuana users may be related to the deep inhalation and breath-holding seen in marijuana users, but not tobacco users or, alternatively, marijuana may have some direct, chronic effect on airway function. Pletcher et al. [59•] examined 5,016 men who were followed for 20 years and tested at years $2,5,10$, and $20 ; 54 \%$ of the sample used cigarettes and/or marijuana at least once. The investigators found no significant interactions between tobacco and marijuana exposure for $\mathrm{FEV}_{1}$ or $\mathrm{FVC}$. Marijuana users were more likely to have an increase in $\mathrm{FEV}_{1}$ and FVC, but in the few heavy marijuana users in the study (over 40 joint-years), there was a decrease in $\mathrm{FEV}_{1}$ and a 
significant increase in FVC, suggesting an increase in airway resistance along with a significant increase in lung volume.

Since 1990, three reviews have summarized pulmonary changes found in individuals who smoke marijuana [60-62]. These changes include lung injury, alveolar macrophage dysfunction, and an increased risk of pulmonary infections and respiratory cancer. The reviewers also report that shortterm use of marijuana is associated with modest bronchodilation, chronic cough, and increased sputum production, while chronic exposure to THC is associated with depressed inflammatory reactions that could lead to increased pulmonary infections.

A review of 34 articles on the impact of marijuana smoking on pulmonary function and respiratory complications explored the results of airflow studies in short- and longterm marijuana users [63]. Eleven studies found an association between short-term marijuana use and bronchodilation, demonstrated by an increase in $\mathrm{FEV}_{1}$. In the studies looking at lung changes in long-term marijuana users, the review found no consistent association between long-term use and measures of air flow obstruction. Fourteen studies that assessed respiratory complications found increased cough, sputum productivity, and wheezing in marijuana smokers. Limitations were found in the quality of some of the studies reviewed, particularly in controlling for confounders such as concurrent tobacco smoking.

Other studies in the last 25 years have suggested that, compared with non-marijuana users and non-smokers, marijuana users were more at risk for experiencing respiratory dysfunction, including symptoms of chronic bronchitis, increased mucus production, wheezing, increased hyperinflation, FVC, and residual volume in respiratory function tests [64-67].

Additionally, marijuana may be an aeroallergen for some individuals and some may be at risk for marijuana allergy. In one study, cannabis might be a clinically important allergen in certain patients; $61 \%(78 / 127)$ of the participants tested positive for cannabis in allergy skin testing where participants lived in areas where cannabis grows naturally [68].

\section{Cardiovascular Disease Risk}

The endocannabinoids and phytocannabinoids both bind with cannabinoid receptors in the cardiac endocannabinoid system, and several studies have reported adverse cardiac effects with the use of marijuana [69, 70]. It is already known that occasional marijuana use is associated with an acute increase in heart rate, palpitations, and orthostatic hypotension. Other cardiovascular diseases are possible and are reviewed below.

As discussed below, conflicting findings have been published regarding the risk of mortality in marijuana use and acute myocardial infarction. Malinowska et al. [71•] reviewed the role of the cannabinoids and blood pressure regulation, and found that marijuana use in humans results in two cardiovascular phases. In phase 1, there is an increase in heart rate and a slight increase in blood pressure. This reaction may be related to an increase in sympathetic stimulation and a decrease in parasympathetic stimulation. In phase 2, orthostatic hypotension is the predominant sign, with a decrease in vascular resistance attributed to CB1 receptor stimulation. In chronic marijuana users, the effects of the cannabinoids on heart rate and blood pressure are longerlasting and may be associated with a variety of adverse effects. In susceptible individuals, an increase in heart rate could result in cardiac ischemia and the arrhythmic effects of the catecholamines. Because marijuana has an analgesic effect, long-term users may not experience typical pain associated with cardiac ischemia and thus might delay medical help. Additionally, there may be an impairment of cardiac oxygenation due to the effect of marijuana smoke on increasing carboxyhemoglobin and stimulation of cell stress.

Some studies have shown an increase risk of acute myocardial infarction (AMI) associated with marijuana use, including a study showing an increased risk (4.8\%) of AMI within $1 \mathrm{~h}$ of smoking marijuana compared with those who did not smoke marijuana [72]. In a follow-up study, Frost et al. [73.] analyzed the hazard ratio for patients and mortality rate among marijuana users, and found no statistically significant association between marijuana use and mortality. Rodondi et al. [74] did not find an increased risk of AMI in marijuana-using participants in a 15 -year longitudinal study. However, compared with others, the marijuana users had a higher caloric intake, drank more alcohol, and were more likely to have an elevated systolic blood pressure and lower plasma triglycerides. Based on a recent prospective cohort study of the mortality rate after AMI in marijuana users, the risk of cardiovascular death seems to be low in most marijuana users; however, the use of marijuana may contribute to unhealthy lifestyles and risky behavior that can increase post-AMI mortality in those individuals with coronary heart disease [75].

A healthy debate continues to be held regarding whether the growing number of reported cases of cannabinoid arteritis represents a distinct and separate disease from thromboangiitis obliterans. In a review of cannabis arteritis, Peyrot et al. [76] reported that since 1960, more than 50 cases of arteritis, similar to thromboangiitis obliterans, have been reported by marijuana users who did not smoke cigarettes. Cannabis arteritis may be analogous to thromboarteritis obliterans seen in cigarette smokers, and Peyrot et al. [76] suggest that cannabis arteritis may be a cause of juvenile peripheral obstructive arterial disease. Disdier et al. [77] described recent cases of cannabis arteritis in a sample of patients who were moderate tobacco and regular marijuana users. Arteriographic studies found distal abnormalities similar to Buerger's disease 
(thromboangiitis obliterans) with changes in the architecture of the vasonervorum.

\section{Neurologic Disease Risk}

Several anatomical and functional neurological abnormalities have been associated with marijuana use, and numerous studies have examined white and gray cerebral matter differences and functional brain activation in marijuana users compared with non-users, with mixed results [78-86]. If proven that marijuana use changes brain volume and brain activation in various areas of the cerebrum, the potential clinical ramifications may include verbal learning deficiencies, associative learning, attention, and alertness [81].

Gonzalez [87] reviewed the scientific literature related to neurobehavioral function and marijuana use. He found that in acute intoxication, subjective mental status was altered, but that the reporting of signs and symptoms of brain function and neuropsychological performance were not consistent in the literature. Frequent heavy users of marijuana were more likely to have neuropsychological deficits. Pope et al. [88] reviewed the literature for studies where participants were given marijuana and then studied (drug-administration studies), and studies where heavy marijuana users abstained before participating in the study (naturalistic studies). Although marijuana use 12-24 $\mathrm{h}$ before testing was associated with changes in attention, psychomotor task ability, and shortterm memory, there were insufficient data in the studies reviewed for any long-term effects on the CNS. Any longterm effects of residual drug on the CNS could be influenced by the acute effects of the drug, the susceptibility of the user, or any pre-existing psychiatric disorder .

In a meta-analysis, investigators examined eight cognitive domains within 11 of 1,014 studies on the residual neurocognitive effects of marijuana use [89]. For six of the domains there was an effect size of zero; however, there was an increased effect size between marijuana use and learning and forgetting. The authors concluded that chronic users seemed to have a decrease in the ability to learn and to remember information. However, they suggest the small effect size of the findings might indicate an acceptable margin of safety if marijuana is used therapeutically.

Despite these studies, marijuana use has otherwise been associated with vascular disease in the CNS. Several recent cases of ischemic strokes associated with marijuana use are present in the recent literature [90-92]. Furthermore, a recent vascular study of marijuana users and controls seemed to indicate that chronic marijuana users may be at risk for stroke [93]. In a recent review of cases of marijuana-related cerebral ischemic events, the author concluded that cerebral vasospasm appeared to be a likely cause of the ischemic events, but did not rule out incidence of emboli of cardiac origin and systemic hypotension due to marijuana use [94].

There may be a risk of tardive dyskinesia due to marijuana exposure [95]. In addition, at this point a paucity of literature has described exposure to marijuana and transient amnesia [96], ataxia [97], and propriospinal myoclonus [98], and spasticity [99]. Several studies have also examined marijuana use and resultant memory and cognitive function with mixed results [100-104].

\section{Ocular Disease Risks}

Some reviews and descriptive reports have indicated that use of marijuana can result in a variety of optical conditions, including image alteration, distorted vision, and photosensitivity [105, 106]. Most of these effects were not found to be harmful or long lasting. However, one of the more controversial topics related to marijuana use and ocular health is the role of cannabinoids in treating glaucoma. Despite numerous claims and support of alternative medicine promoters, marijuana has not been accepted as an effective treatment of glaucoma. Although THC does seem to decrease intraocular pressure, marijuana's effect in reducing ocular pressure is short lived and the drug would need to be smoked every $3-4 \mathrm{~h}$ to maintain a lower pressure [107]. Previously, the National Eye Institute had supported studies exploring the effectiveness of smoked marijuana, as well as THC-containing drugs, but subsequently found that marijuana was not as effective as current standard treatment of glaucoma [108].

\section{Renal and Urological Disease Risk}

Illicit substances, including marijuana, may be associated with renal and urological dysfunction, including glomerular, interstitial, and renal vascular disease [109]. Vupputuri et al. [110] studied the association between marijuana use in hypertensive patients and the risk for developing mild renal disease, and did not find an association of marijuana use with renal disease.

A review by Thompson [111] looked at the causes of male infertility and included marijuana as one of the potential causes. Marijuana can decrease spermatogenesis and circulating testosterone levels [112]. In a case-control study, investigators explored pyospermia in infertile men and the relationship to marijuana smoking [113]. Compared with non-users, significant increases in leukocytes in seminal fluid were found in marijuana users, but did not have a significant difference in multivariable analyses. Johnson et al. [114] reviewed the data from the 1981-1983 Epidemiologic Catchment Area Project to study the association between sexual dysfunction and drug and alcohol use. Controlling for 
confounders, inhibited orgasm and painful sex were associated with marijuana and alcohol use.

\section{Digestive Disease Risks}

There exist more than three dozen articles on "marijuana hyperemesis." Although many of the articles included case descriptions, some articles were case series, including a retrospective study involving marijuana users who experienced nausea and vomiting; stopping marijuana use caused the symptoms to dissipate [115•]. The authors report that marijuana hyperemesis is often under-diagnosed and under-reported.

\section{Gynecological Disease Risks}

Marijuana, perhaps alone or with other illicit drug use, may impart infertility to women [116]. In a case control study, investigators studied the risk of infertility in a sample of infertile women who used illicit drugs, including marijuana, and they found that women who used marijuana within 1 year of trying to become pregnant were not likely to become pregnant [117]. Two studies looked at the risk of vaginal infections and marijuana use. Marijuana users were six times more likely to develop Trichomonas vaginalis infection than non-marijuana users [118]. In another study to determine the risk of vaginal yeast infections in marijuana users, investigators found marijuana use in the last 4 months was associated with the presence of vaginal yeast [119].

\section{Hematologic and Immunologic Disease Risk}

Except for that reported above, no epidemiological studies in the last 20 years have reported on marijuana use and disorders of the hematopoietic and lymphatic systems, despite strong research evidence that $\mathrm{CB} 2$ receptors are found predominantly on cells involved in immunity and inflammation. Cannabinoid receptors (CB2) are expressed in human immune tissues and leukocyte subtypes [120]. Authors recently suggested that the CB2 receptors are required for the development of both $\mathrm{T}$ - and B-lymphocyte subsets [121]. Interestingly, a recent study indicated that there was a decreased risk for non-Hodgkin's lymphoma in lifetime marijuana users [122].

\section{Nutritional and Metabolic Diseases Risks}

Two reviews have examined the nutritional effects of illicit drugs, including marijuana. For the first review, the authors examined several illicit drugs, including marijuana, and determined that they affect food and liquid intake, can alter taste perception and affect preferences, and affect body weight [123]. Articles reviewed indicate that during the use of marijuana, or during withdrawal, there can be major changes in food selection and intake, including either weight gain or loss. Besides marijuana, cocaine and nicotine were also targets of this study. In a second review, the authors reviewed the role of the $\mathrm{CB} 1$ and $\mathrm{CB} 2$ receptors and their action on nutritional/ energy balance [124]. In studies that the reviewers examined, they found that overactivity of the cannabinoids may lead to abdominal obesity, dyslipidemia, and hyperglycemia. Furthermore, clinical trials using CB1 antagonists have shown a decrease in food intake, decreased adipose cell volume, and a return of more functional metabolic balance.

\section{Conclusions}

The use of illicit substances contributes to significant morbidity and mortality worldwide, and substance use is a leading cause of preventable death [125]. Substance use and substance use disorders impart consequences to the mental, physical, and environmental health of people. Like other substances of abuse, exposure to inhaled marijuana has a biological basis for causing physical health effectscannabinoid receptors are endogenous to the human body. While a debate rages over the merits of medical or recreational marijuana, the number of patients who use marijuana has increased and will likely continue to increase. Therefore, it is incumbent for healthcare providers to know the healthcare effects of marijuana to anticipate physical health effects of this exposure.

Advocacy, opinion, and politics may cloud perception of the merits of marijuana's legal use [126]. However, the peerreviewed literature is the most objective means to examine purported and realized health effects of marijuana exposure. In this review, we examined the recent (since 1998) literature regarding associations of the health effects to marijuana exposure. We found evidence that marijuana seems to have physical health effects in humans aside from mental health, behavioral, and societal morbidity, and there is a biological basis for many of these effects. For example, marijuana use is associated with diseases of the liver (particularly with coexisting hepatitis C), lungs, heart, and vasculature. For clinicians, knowing these associations will enhance their ability to address these incident (or on-going) physical illnesses that may occur secondary to marijuana use.

Certainly, more research regarding the direct physical consequences of marijuana exposure is required. This research may be difficult in the current political climate of the USA [127]. We found much of the existing literature lacking good, sound evidence. We concur with many of the authors that there are significant problems with the evidence presented. 
This includes problems in the ability to quantify the marijuana exposure and the route of exposure (assumed to be inhaled); the reliability of self-report of marijuana and other drug use (including fear of legal consequences of disclosure); selfselection to participate in the studies; the lack of knowledge of pre-disposition or existing medical conditions of participants; confounding cigarette, nicotine, alcohol and other drug use effects; and the influence of incident or existing mental disorders on the exacerbation or incidence of physical health conditions. Certainly, many of the studies were of small sample size or were case reports, and we encountered too few longitudinal and randomized controlled studies that have enough power to make clear associations for medical harms associated with marijuana use. Perhaps as more people are exposed to marijuana, the health effects of its use will be found in large cohort studies that are (or are not) intended to examine health-related effects of the substance. Certainly, these studies should assess for marijuana use.

This review has several limitations. We did not evaluate the literature prior to 1998, although findings of the remote literature seems to be concordant with our findings [14]. We only examined the English literature found in MEDLINE and PubMed in order to assess the "best" literature, and while we did not rate the quality of the findings (or the journal), we avoided information that was speculative. Certainly, publication bias may have affected our ability to examine research that was negative in any specific association. We did not report here on the medical benefits of marijuana as an anti-emetic or an analgesic, or other health benefits. As mentioned above, we did not examine the associated risks of drug administration, mental health, behavioral, or societal consequences of marijuana use, as we concentrated on the direct physical health effects of the substance. There is substantial literature on these effects, and they should not be discounted by the clinician [18].

Despite these limitations, this review should provide some warning to the clinician of the evidence of health effects of increasingly common recreational, medicinal, or illicit marijuana use. As the biological and patho-physiological understanding of endogenous cannabinoid systems are elucidated, more presumptive disease associations can, and should, be examined.

\begin{abstract}
Acknowledgments This material is the result of work supported with resources from, and the use of facilities at, the VA Pittsburgh Healthcare System, Pittsburgh, Pennsylvania. The content of this work does not necessarily represent the views, opinions, or policies of the Department of Veterans Affairs or the United States government.
\end{abstract}

\section{Compliance with Ethics Guidelines}

Conflict of Interest Adam J. Gordon has received research support from National Institutes of Health, Department of Veterans Affairs, and Substance Abuse and Mental Health Services Administration and royalties from Cambridge University Press and UpToDate.
James W. Conley and Joanne M. Gordon declare that they have no conflict of interest.

Human and Animal Rights and Informed Consent This article does not contain any studies with human or animal subjects performed by any of the authors.

\section{References}

Papers of particular interest, published recently, have been highlighted as:

- Of importance

1. Wall MM, Poh E, Cerda M, et al. Adolescent marijuana use from 2002 to 2008: higher in states with medical marijuana laws, cause still unclear. Ann Epidemiol. 2011;21:714-6.

2. Drug Enforcement Administration. Drug Scheduling. Available at http://www.justice.gov/dea/druginfo/ds.shtml. Accessed September 2013.

3. Eidelman WS. Should physicians support the medical use of marijuana? Yes: it can be effective when all else fails. Point West J Med. 2002;176:76.

4. Grinspoon L, Bakalar JB. Marihuana. The forbidden medicine. New Haven: Yale University Press; 1995.

5. Kassirer JP. Federal foolishness and marijuana. N Engl J Med. 1997;336:366-7.

6. Annas GJ. Reefer madness - the federal response to California's medical-marijuana law. N Engl J Med. 1997;337:435-9.

7. American Psychiatric Association. Diagnostic and statistical manual of mental disorders. 5th ed. Arlington: American Psychiatric Publishing; 2013.

8. United Nations Office on Drugs and Crime. World drug report 2012. New York: United Nations; 2012.

9. Pew Research Center. Majority now supports legalizing marijuana. Washington, DC: People Press; 2013.

10. Johnston LD, O'Malley PM, Bachman JG, Schulenberg JE. Monitoring the future national survey results on drug use: 2012 overview, key findings on adolescent drug use. Ann Arbor: Institute for Social Research, The University of Michigan; 2013.

11. Centers for Disease Control and Prevention (CDC). Youth risk behavior surveillance-United States, 2011. MMWR Morb Mortal Wkly Rep; 2012

12. American Society of Addiction Medicine. White Paper on statelevel proposals to legalize marijuana. Available at http://www.asam. org/advocacy/find-a-policy-statement/view-policy-statement/ public-policy-statements/2012/07/30/state-level-proposals-tolegalize-marijuana. Accessed September 2013.

13. Budney AJ, Moore BA. Development and consequences of cannabis dependence. J Clin Pharmacol. 2002;42(11 Suppl):28S-33S.

14. Gordon AJ, Gordon JM, Carl K, et al. Physical illness and drugs of abuse: a review of the evidence. Cambridge: Cambridge University Press; 2010.

15. Graham AW, Schultz TK, editors. Principles of addiction medicine. 2nd ed. Chevy Chase: American Society of Addiction Medicine; 1998.

16. Frances RJ, Miller SI, Mack AH, editors. Clinical textbook of addictive disorders. 3rd ed. New York: The Guilford Press; 2005.

17. Brick J, editor. Handbook of the medical consequences of alcohol and drug abuse. Binghamton: The Haworth Press; 2004.

18. Hall W, Degenhardt L. Adverse health effects of non-medical cannabis use. Lancet. 2009;374:1383-91. 
19. Lee MJ. Marihuana and tobacco use in pregnancy. Obstet Gynecol Clin North Am. 1998;25:65-83.

20. Kuczkowski KM. Marijuana in pregnancy. Ann Acad Med Singapore. 2004;33:336-9.

21. Sundram S. Cannabis and neurodevelopment: implications for psychiatric disorders. Hum Psychopharmacol. 2006;21:245-54.

22. Behnke M, Eyler FD. The consequences of prenatal substance use for the developing fetus, newborn, and young child. Int J Addict. 1993;28:1341-91.

23. Schempf AH. Illicit drug use and neonatal outcomes: a critical review. Obstet Gynecol Surv. 2007;62:749-57.

24. Day NL, Richardson GA. Prenatal marijuana use: epidemiology, methodologic issues, and infant outcome. Clin Perinatol. 1991;18:77-91.

25. Hall W, Degenhardt L. Cannabis use and psychosis: a review of clinical and epidemiological evidence. Aust N Z J Psychiatry. 2000;34:26-34.

26. Friedman H, Pross S, Klein TW. Addictive drugs and their relationship with infectious diseases. FEMS Immunol Med Microbiol. 2006;47:330-42.

27. Klein TW, Friedman H, Specter S. Marijuana, immunity and infection. J Neuroimmunol. 1998;83:102-15.

28. Munckhof WJ, Konstantinos A, Wamsley M, et al. A cluster of tuberculosis associated with use of a marijuana water pipe. Int J Tuberc Lung Dis. 2003;7:860-5.

29. Oeltmann JE, Oren E, Haddad MB, et al. Tuberculosis outbreak in marijuana users, Seattle, Washington, 2004. Emerg Infect Dis. 2006;12:1156.

30. Krause G, Blackmore C, Wiersma S, et al. Marijuana use and social networks in a community outbreak of meningococcal disease. South Med J. 2001;94:482-5.

31. Finn R, Groves C, Coe M, et al. Cluster of serogroup C meningococcal disease associated with attendance at a party. South Med J. 2001;94:1192-4.

32. Liau A, di Clemente RJ, Wingood GM. Associations between biologically confirmed marijuana use and laboratory-confirmed sexually transmitted diseases among African American adolescent females. Sex Transm Dis. 2002;29:387-90.

33. Darling MR, Arendorf TM, Coldrey NA. Effect of cannabis use on oral candidal carriage. J Oral Pathol Med. 1990;19:319-21.

34. Darling MR, Arendorf TM. Review of the effects of cannabis smoking on oral health. Int Dent J. 1992;42:19-22.

35. Hezode C, Zafrani ES, Roudot-Thoraval F, et al. Daily cannabis use: a novel risk factor of steatosis severity in patients with chronic hepatitis C. Gastroenterology. 2008;134:432-9.

36. Ishida JH, Peters MG, Jin C, et al. Influence of cannabis use on severity of hepatitis C disease. Clin Gastroenterol Hepatol. 2008;6:69-75.

37. Hashibe M, Ford DE, Zhang ZF. Marijuana smoking and head and neck cancer. J Clin Pharmacol. 2002;42(11 Suppl):103S-7S.

38. Hashibe M, Straif K, Tashkin DP, et al. Epidemiologic review of marijuana use and cancer risk. Alcohol. 2005;35:265-75.

39. Mehra R, Moore BA, Crothers K, et al. The association between marijuana smoking and lung cancer: a systematic review. Arch Intern Med. 2006;166:1359-67.

40. Carriot F, Sasco AJ. Cannabis and cancer. Rev Epidemiol Sante Publique. 2000;48:473-83.

41. Zhang ZF, Morgenstern H, Spitz MR, et al. Marijuana use and increased risk of squamous cell carcinoma of the head and neck. Cancer Epidemiol Biomarkers Prev. 1999;8:1071-8.

42. Rosenblatt KA, Daling JR, Chen C, et al. Marijuana use and risk of oral squamous cell carcinoma. Cancer Res. 2004;64:4049-54.

43. Nieder AM, Lipke MC, Madjar S. Transitional cell carcinoma associated with marijuana: case report and review of the literature. Urology. 2006;67:200.

44. Chacko JA, Heiner JG, Siu W, et al. Association between marijuana use and transitional cell carcinoma. Urology. 2006;67:100-4.
45. Daling JR, Doody DR, Sun X, et al. Association of marijuana use and the incidence of testicular germ cell tumors. Cancer. 2009;115: 1215-23.

46. Trabert B, Sigurdson AJ, Sweeney AM, et al. Marijuana use and testicular germ cell tumors. Cancer. 2011;117:848-53.

47. Lacson JC, Carroll JD, Tuazon E, et al. Population-based casecontrol study of recreational drug use and testis cancer risk confirms an association between marijuana use and nonseminoma risk. Cancer. 2012;118:5374-83.

48. Berthiller J, Lee YC, Boffetta P, et al. Marijuana smoking and the risk of head and neck cancer: pooled analysis in the INHANCE consortium. Cancer Epidemiol Biomarkers Prev. 2009;18:1544-51.

49. Aldington S, Harwood M, Cox B, et al. Cannabis use and cancer of the head and neck: case-control study. Otolaryngol Head Neck Surg. 2008;138:374-80.

50. Hashibe M, Morgenstern H, Cui Y, et al. Marijuana use and the risk of lung and upper aerodigestive tract cancers: results of a population-based case-control study. Cancer Epidemiol Biomarkers Prev. 2006;15:1829-34.

51. Voirin N, Berthiller J, Benhaim-Luzon V, et al. Risk of lung cancer and past use of cannabis in Tunisia. J Thorac Oncol. 2006;1:577-9.

52. Aldington S, Harwood M, Cox B, et al. Cannabis use and risk of lung cancer: a case-control study. Eur Respir J. 2008;31:280-6.

53. Taylor III FM. Marijuana as a potential respiratory tract carcinogen: a retrospective analysis of a community hospital population. South Med J. 1988;81:1213-6.

54. Cho CM, Hirsch R, Johnstone S. General and oral health implications of cannabis use. Aust Dent J. 2005;50:70-4.

55. Darling MR, Arendorf TM. Effects of cannabis smoking on oral soft tissues. Community Dent Oral Epidemiol. 1993;21:78-81.

56. Thomson WM, Poulton R, Broadbent JM, et al. Cannabis smoking and periodontal disease among young adults. JAMA. 2008;299: 525-31.

57. - Lee MH, Hancox RJ. Effects of smoking cannabis on lung function. Expert Rev Respir Med. 2011;5:537-46. Expert review of marijuana-induced respiratory inflammation and dysfunction. .

58. - Hancox RJ, Poulton R, Ely M, et al. Effects of cannabis on lung function: a population-based cohort study. Eur Respir J. 2010;35:42-7. Large longitudinal styudy of marijuana users over 29-year period. .

59. - Pletcher MJ, Vittinghoff E, Kalhan R, et al. Association between marijuana exposure and pulmonary function over 20 years. JAMA. 2012;307:173-81. Twenty-year longitudinal study; more harm may be associated with heavy, long-term use than occasional marijuana use. .

60. Tashkin DP. Smoked marijuana as a cause of lung injury. Monaldi Arch Chest Dis. 2005;63:93-100.

61. Tashkin DP. Airway effects of marijuana, cocaine, and other inhaled illicit agents. Curr Opin Pulm Med. 2001;7:43-61.

62. Tashkin DP. Pulmonary complications of smoked substance abuse. West J Med. 1990;152:525-30.

63. Tetrault JM, Crothers K, Moore BA, et al. Effects of marijuana smoking on pulmonary function and respiratory complications: a systematic review. Arch Intern Med. 2007;167:221-8.

64. Polen MR, Sidney S, Tekawa IS, et al. Health care use by frequent marijuana smokers who do not smoke tobacco. West J Med. 1993;158:596-601.

65. Taylor DR, Poulton R, Moffitt TE, et al. The respiratory effects of cannabis dependence in young adults. Addiction. 2000;95: 1669-77.

66. Taylor DR, Fergusson DM, Milne BJ, et al. A longitudinal study of the effects of tobacco and cannabis exposure on lung function in young adults. Addiction. 2002;97:1055-61.

67. Moore BA, Augustson EM, Moser RP, et al. Respiratory effects of marijuana and tobacco use in a U.S. sample. J Gen Intern Med. 2005;20:33-7. 
68. Stokes JR, Hartel R, Ford LB, et al. Cannabis (hemp) positive skin tests and respiratory symptoms. Ann Allergy Asthma Immunol. 2000;85:238-40

69. Sidney S. Cardiovascular consequences of marijuana use. J Clin Pharmacol. 2002;42(11 Suppl):64S-70S.

70. Aryana A, Williams MA. Marijuana as a trigger of cardiovascular events: speculation or scientific certainty? Int J Cardiol. 2007;118: $141-4$.

71. - Malinowska B, Baranowska-Kuczko M, Schlicker E. Triphasic blood pressure responses to cannabinoids: do we understand the mechanism? Br J Pharmacol. 2012;165:2073-88. Review of physiological cardiovascular effects related to cannabinoids.

72. Mittleman MA, Lewis RA, Maclure M, et al. Triggering myocardial infarction by marijuana. Circulation. 2001;103:2805-9.

73. - Frost L, Mostofsky E, Rosenbloom JI, et al. Marijuana use and long-term mortality among survivors of acute myocardial infarction. Am Heart J. 2013;165:170-5. Eighteen-year follow-up of cardiovascular mortality in marijuana users. .

74. Rodondi N, Pletcher MJ, Liu K, et al. Marijuana use, diet, body mass index, and cardiovascular risk factors (from the CARDIA study). Am J Cardiol. 2006;98:478-84.

75. Mukamal KJ, Maclure M, Muller JE, et al. An exploratory prospective study of marijuana use and mortality following acute myocardial infarction. Am Heart J. 2008;155:465-70.

76. Peyrot I, Garsaud AM, Saint-Cyr I, et al. Cannabis arteritis: a new case report and a review of literature. J Eur Acad Dermatol Venereol. 2007;21:388-91.

77. Disdier P, Granel B, Serratrice J, et al. Cannabis arteritis revisitedten new case reports. Angiology. 2001;52:1-5.

78. Block RI, O'Leary DS, Ehrhardt JC, et al. Effects of frequent marijuana use on brain tissue volume and composition. Neuroreport. 2000;11:491-6.

79. Matochik JA, Eldreth DA, Cadet JL, et al. Altered brain tissue composition in heavy marijuana users. Drug Alcohol Depend. 2005;77:23-30.

80. Medina KL, Schweinsburg AD, Cohen-Zion M, et al. Effects of alcohol and combined marijuana and alcohol use during adolescence on hippocampal volume and asymmetry. Neurotoxicol Teratol. 2007;29:141-52.

81. Jager G, van Hell HH, De Win MM, et al. Effects of frequent cannabis use on hippocampal activity during an associative memory task. Eur Neuropsychopharmacol. 2007;17:289-97.

82. Jacobsen LK, Mencl WE, Westerveld M, et al. Impact of cannabis use on brain function in adolescents. Ann N Y Acad Sci. 2004;1021: 384-90.

83. Pillay SS, Rogowska J, Kanayama G, et al. Cannabis and motor function: fMRI changes following 28 days of discontinuation. Exp Clin Psychopharmacol. 2008;16:22-32.

84. Chang L, Yakupov R, Cloak C, et al. Marijuana use is associated with a reorganized visual-attention network and cerebellar hypoactivation. Brain. 2006;129:1096-112.

85. Kanayama G, Rogowska J, Pope HG, et al. Spatial working memory in heavy cannabis users: a functional magnetic resonance imaging study. Psychopharmacology (Berl). 2004;176:239-47.

86. Tapert SF, Schweinsburg AD, Drummond SP, et al. Functional MRI of inhibitory processing in abstinent adolescent marijuana users. Psychopharmacology (Berl). 2007;194:173-83.

87. Gonzalez R. Acute and non-acute effects of cannabis on brain functioning and neuropsychological performance. Neuropsychol Rev. 2007;17:347-61.

88. Pope Jr HG, Gruber AJ, Yurgelun-Todd D. The residual neuropsychological effects of cannabis: the current status of research. Drug Alcohol Depend. 1995;38:25-34.

89. Grant I, Gonzalez R, Carey CL, et al. Non-acute (residual) neurocognitive effects of cannabis use: a meta-analytic study. J Int Neuropsychol Soc. 2003;9:679-89.
90. Zachariah SB. Stroke after heavy marijuana smoking. Stroke. 1991;22:406-9.

91. Geller T, Loftis L, Brink DS. Cerebellar infarction in adolescent males associated with acute marijuana use. Pediatrics. 2004;113:e365-70.

92. Finsterer J, Christian P, Wolfgang K. Occipital stroke shortly after cannabis consumption. Clin Neurol Neurosurg. 2004;106:305-8.

93. Herning RI, Better WE, Tate K, et al. Marijuana abusers are at increased risk for stroke. Preliminary evidence from cerebrovascular perfusion data. Ann N Y Acad Sci. 2001;939:413-5.

94. Moussouttas M. Cannabis use and cerebrovascular disease. Neurologist. 2004;10:47-53.

95. Zaretsky A, Rector NA, Seeman MV, et al. Current cannabis use and tardive dyskinesia. Schizophr Res. 1993;11:3-8.

96. Stracciari A, Guarino M, Crespi C, et al. Transient amnesia triggered by acute marijuana intoxication. Eur J Neurol. 1999;6:521-3.

97. Bonkowsky JL, Sarco D, Pomeroy SL. Ataxia and shaking in a 2year-old girl: acute marijuana intoxication presenting as seizure. Pediatr Emerg Care. 2005;21:527-8.

98. Lozsadi DA, Forster A, Fletcher NA. Cannabis-induced propriospinal myoclonus. Mov Disord. 2004;19:708-9.

99. Malec J, Harvey RF, Cayner JJ. Cannabis effect on spasticity in spinal cord injury. Arch Phys Med Rehabil. 1982;63:116-8.

100. Schwartz LS, Taylor JR. Attitudes of mental health professionals toward alcoholism recognition and treatment. Am J Drug Alcohol Abuse. 1989;15:321-37.

101. Wilson WH, Ellinwood EH, Mathew RJ, et al. Effects of marijuana on performance of a computerized cognitive-neuromotor test battery. Psychiatry Res. 1994;51:115-25.

102. Rizzo M, Lamers CT, Sauer CG, et al. Impaired perception of selfmotion (heading) in abstinent ecstasy and marijuana users. Psychopharmacology (Berl). 2005;179:559-66.

103. Messinis L, Kyprianidou A, Malefaki S, et al. Neuropsychological deficits in long-term frequent cannabis users. Neurology. 2006;66:737-9.

104. Ramaekers JG, Kauert G, van Ruitenbeek P, et al. High-potency marijuana impairs executive function and inhibitory motor control. Neuropsychopharmacology. 2006;31:2296-303.

105. Urey JC. Some ocular manifestations of systemic drug abuse. J Am Optom Assoc. 1991;62:832-42.

106. Levi L, Miller NR. Visual illusions associated with previous drug abuse. J Clin Neuroophthalmol. 1990;10:103-10.

107. Parikh RS, Parikh SR. Alternative therapy in glaucoma management: is there any role? Indian J Ophthalmol. 2011;59:S158-60.

108. NEI. NEI statement: glaucoma and marijuana use. Available at nei.nih.gov/news/statements/marij.asp. Accessed June 2013.

109. Crowe AV, Howse M, Bell GM, et al. Substance abuse and the kidney. QJM. 2000;93:147-52.

110. Vupputuri S, Batuman V, Muntner P, et al. The risk for mild kidney function decline associated with illicit drug use among hypertensive men. Am J Kidney Dis. 2004;43:629-35.

111. Thompson ST. Preventable causes of male infertility. World J Urol. 1993;11:111-9.

112. Ramos JA, Bianco FJ. The role of cannabinoids in prostate cancer: basic science perspective and potential clinical applications. Indian J Urol. 2012;28:9-14.

113. Close CE, Roberts PL, Berger RE. Cigarettes, alcohol and marijuana are related to pyospermia in infertile men. $\mathrm{J}$ Urol. 1990;144:900-3.

114. Johnson SD, Phelps DL, Cottler LB. The association of sexual dysfunction and substance use among a community epidemiological sample. Arch Sex Behav. 2004;33:55-63.

115. - Simonetto DA, Oxentenko AS, Herman ML, et al. Cannabinoid hyperemesis: a case series of 98 patients. Mayo Clin Proc. 2012;87: 114-9. Report of emerging under-reported consequence of marijuana use. .

116. Buck GM, Sever LE, Batt RE, et al. Life-style factors and female infertility. Epidemiology. 1997;8:435-41. 
117. Mueller BA, Daling JR, Weiss NS, et al. Recreational drug use and the risk of primary infertility. Epidemiology. 1990;1:195-200.

118. Crosby R, di Clemente RJ, Wingood GM, et al. Predictors of infection with Trichomonas vaginalis: a prospective study of low income African-American adolescent females. Sex Transm Infect. 2002;78:360-4.

119. Beigi RH, Meyn LA, Moore DM, et al. Vaginal yeast colonization in nonpregnant women: a longitudinal study. Obstet Gynecol. 2004;104:926-30.

120. Galiègue S, Mary S, Marchand J, et al. Expression of central and peripheral cannabinoid receptors in human immune tissues and leukocyte subpopulations. Eur J Biochem. 1995;232:54-61.

121. Ziring D, Wei B, Velazquez P, et al. Formation of B and T cell subsets require the cannabinoid receptor CB2. Immunogenetics. 2006;58:714-25.
122. Holly EA, Lele C, Bracci PM, et al. Case-control study of nonHodgkin's lymphoma among women and heterosexual men in the San Francisco Bay Area, California. Am J Epidemiol. 1999;150: 375-89.

123. Mohs ME, Watson RR, Leonard-Green T. Nutritional effects of marijuana, heroin, cocaine, and nicotine. J Am Diet Assoc. 1990;90:1261-7.

124. Matias I, Di MV. Endocannabinoids and the control of energy balance. Trends Endocrinol Metab. 2007;18:27-37.

125. Mokdad AH, Marks JS, Stroup DF, et al. Actual causes of death in the United States, 2000. JAMA. 2004;291:1238-45.

126. Bostwick JM. Blurred boundaries: the therapeutics and politics of medical marijuana. Mayo Clin Proc. 2012;87:172-86.

127. Harris, G. Researchers find study of medical marijuana discouraged. New York Times. 1-19-2010. Accessed on July 72013. 